\title{
LETTER
}

\section{Long live dynamic parameters!}

\author{
Frederic Michard \\ See related viewpoint by Sondergaard, http://ccforum.com/content/17/6/327
}

In a recent article about pulse pressure variation (PPV), after 4 pages of physiologic explanations, Dr Sondergaard finally concluded that the subject is an exceptional demonstration of physiology but hardly guides the management of critically ill patients' [1]. If I agree with the first part of this statement (I and others spent years dissecting the complex physiology behind PPV), I strongly disagree with the second part of the sentence for three reasons, which are not opinions but facts.

First, PPV and stroke volume variation (SVV) are increasingly used to guide fluid therapy both in the operating theater and in ICUs. This was confirmed by published peerreviewed surveys, showing that the use of dynamic parameters increased from $1 \%$ in 1998 [2] to $45 \%$ in 2012 [3]. If dynamic parameters were not clinically useful one can doubt clinicians would have embraced this concept as they did.
Second, PPV and SVV are today displayed on almost all bedside and hemodynamic monitors, next to other vital signs such as the heart rate, blood pressure and arterial oxygen saturation. If medical device industry has financial interests in doing this, it is not fool enough to make research and development investments on something caregivers do not value in their clinical practice.

Third, at least 10 randomized controlled trials have demonstrated that hemodynamic strategies based on PPV or SVV monitoring allow a significant reduction in post-surgical complications and hospital length of stay (Table 1).

So dynamic parameters are well alive and useful for improving patient outcome. Long live dynamic parameters!

Table 1 Randomized controlled trials demonstrating the ability of hemodynamic strategies based on pulse pressure variation or stroke volume variation monitoring to improve postsurgical outcome

\begin{tabular}{|c|c|c|c|}
\hline Study & Surgical population & Hemodynamic goal & Clinical benefit \\
\hline Benes and colleagues, 2010 [4] & Major abdominal & SW $<10 \%$ & Decrease in complications and hospital length of stay \\
\hline Goepfert and colleagues, 2013 [5] & Cardiac & $\mathrm{SW}<10 \%$ & Decrease in complications and ICU length of stay \\
\hline Lopes and colleagues, 2007 [6] & Major abdominal & PPV $<10 \%$ & Decrease in complications and ICU and hospital length of stay \\
\hline Mayer and colleagues, 2010 [7] & Major abdominal & $\mathrm{SW}<12 \%$ & Decrease in complications and hospital length of stay \\
\hline Ramsingh and colleagues, 2013 [8] & Major abdominal & SW $<12 \%$ & $\begin{array}{l}\text { Faster return of gastrointestinal function and decrease in hospital } \\
\text { length of stay }\end{array}$ \\
\hline Salzwedel and colleagues, 2013 [9] & Major abdominal & PPV $<10 \%$ & Decrease in complications \\
\hline Schereen and colleagues, 2013 [10] & Major abdominal & $\mathrm{SW}<10 \%$ & Decrease in surgical site infections \\
\hline Zhang and colleagues, 2012 [11] & Major abdominal & PPV $<11 \%$ & $\begin{array}{l}\text { Faster return of gastrointestinal function and decrease in hospital } \\
\text { length of stay }\end{array}$ \\
\hline Zhang and colleagues, 2013 [12] & Thoracic & $\mathrm{SW}=10 \%$ & Decrease in complications and intubation time \\
\hline Zheng and colleagues, 2013 [13] & Major abdominal & $\mathrm{SW}<12 \%$ & $\begin{array}{l}\text { Faster return of gastrointestinal function and decrease in ICU and } \\
\text { hospital length of stay }\end{array}$ \\
\hline
\end{tabular}

PPV, pulse pressure variation; SVV, stroke volume variation.

Correspondence: frederic_michard@edwards.com

Edwards Lifesciences, 1 Edwards Way, Irvine, CA 92614, USA 
Abbreviations

PPV: Pulse pressure variation; SW: Stroke volume variation.

\section{Competing interests}

FM is a Vice-President, Global Medical Strategy, at Edwards Lifesciences. Of note, the above statements do not support the use of any specific medical device.

\section{Published: 27 Feb 2014}

\section{References}

1. Sondergaard S: Pavane for a pulse pressure variation defunct. Crit Care 2013, 17:327.

2. Boldt J, Lenz M, Kumle B, Papsdorf M: Volume replacement strategies on intensive care units: results from a postal survey. Intensive Care Med 1998, 24:147-151.

3. Srinivasa S, Kahokehr A, Soop M, Taylor M, Hill AG: Goal-directed fluid therapy - a survey of anaesthetists in the UK, USA, Australia and New Zealand. BMC Anesthesiol 2013, 13:5.

4. Benes J, Chytra I, Altmann P, Hluchy M, Kasal E, Svitak R, Pradl R, Stepan M: Intraoperative fluid optimization using stroke volume variation in high risk surgical patients: results of prospective randomized study. Crit Care 2010, 14:R118.

5. Goepfert MS, Richter HP, Eulenburg CZ, Gruetzmacher J, Rafflenbeul E, Roeher K, Sandersleben AV, Diedrichs S, Reichenspurner H, Goetz AE, Reuter DA: Individually optimized hemodynamic therapy reduces complications and length of stay in the intensive care unit: a prospective, randomized controlled trial. Anesthesiology 2013, 119:824-836.

6. Lopes MR, Oliveira MA, Pereira V, Lemos I, Auler J, Michard F: Goal-directed fluid management based on pulse pressure variation monitoring during high-risk surgery: a pilot randomized controlled trial. Crit Care 2007, 11:R100.

7. Mayer J, Boldt J, Mengistu A, Rohm K, Suttner S: Goal-directed intraoperative therapy based on autocalibrated arterial pressure waveform analysis reduces hospital stay in high-risk surgical patients: a randomized, controlled trial. Crit Care 2010, 14:R18.

8. Ramsingh DS, Sanghvi C, Gamboa J, Cannesson M, Applegate RL: Outcome impact of goal directed fluid therapy during high risk abdominal surgery in low to moderate risk patients: a randomized controlled trial. J Clin Monit Comput 2013, 27:249-257.

9. Salzwedel C, Puig J, Carstens A, Bein B, Molnar Z, Kiss K, Hussain A, Belda J, Kirov MY, Sakka SG, Reuter DA: Perioperative goal-directed hemodynamic therapy based on radial arterial pulse pressure variation and continuous cardiac index trending reduces postoperative complications after major abdominal surgery: a multi-center, prospective, randomized study. Crit Care 2013, 17:R191.

10. Scheeren TWL, Wiesenack C, Gerlach H, Marx G: Goal-directed intraoperative fluid therapy guided by stroke volume and its variation in high-risk surgical patients: a prospective randomized multicentre study. J Clin Monit Comput 2013, 27:225-233.

11. Zhang J, Qiao H, He Z, Wang Y, Che X, Liang W: Intraoperative fluid management in open gastrointestinal surgery: goal-directed versus restrictive. Clinics 2012, 67:1149-1155.

12. Zhang J, Chen CQ, Lei XZ, Feng ZY, Zhu SM: Goal-directed fluid optimization based on stroke volume variation and cardiac index during one-lung ventilation in patients undergoing thoracoscopy lobectomy operations: a pilot study. Clinics 2013, 68:1065-1070.

13. Zheng H, Guo H, Ye JR, Chen L, Ma HP: Goal-directed fluid therapy in gastrointestinal surgery in older coronary heart disease patients: randomized trial. World J Surg 2013, 37:2820-2829. 